\title{
Neuropsychological Researches: Experiences and Comments
}

Ivana Leposavic $^{1 *}$, Ljubica Leposavic-Stankovic ${ }^{2}$ and Dragana Djuric-Jocic ${ }^{1}$

${ }^{1}$ Psychiatry Clinic, Clinical Center of Serbia, Belgrade, Serbia

${ }^{2}$ University of Belgrade, School of Medicine, Belgrade, Serbia

*Corresponding author: Ivana Leposavić, Psychiatry Clinic, Clinical Center of Serbia Pasterova 2, 11000 Beograd, Serbia, Tel: 3864 2664293, Fax: 3811 645543; Email: ivana.leposavic@gmail.com

Received Date: August 14, 2014, Accepted Date: November 17, 2014, Published Date: November 25, 2014

Copyright: (c) 2015, Ivana Leposavic et al., This is an open-access article distributed under the terms of the Creative Commons Attribution License, which permits unrestricted use, distribution, and reproduction in any medium, provided the original author and source are credited.

\section{Abstract}

Researches in clinical neuropsychology are numerous and they offer priceless knowledge about cognitive functioning of both healthy and ill persons. The presented mini review has been based on clinical and investigative experience and reflects authors' comments about current challenges concerning neuropsychological investigations.

Keywords: Neuropsychology; Neuropsychological tests; Limits; Neuropsychological diagnostics

\section{Introduction}

Since the second half of the 20th century, when neuropsychology gained status of independent scientific discipline, the areas of its domain have drastically been expanded and have been followed by constant increase of researches. Neuropsychological diagnostics have become an almost unavoidable 'means' in many medical specialties. Nowadays, diagnostics and therapeutic work, as well as working in the research field in various clinical disciplines cannot be envisioned without applying neuropsychological methods. All those experts who deal with description of some forms of disturbed behavior, with neurosurgical interventions, rehabilitation, work- ability evaluation, judicial expertise, who provide for patients and their medical therapy and so on, lean on neuropsychological diagnostics. In short, no other method has been able to undermine the crucial role of neuropsychological evaluation of cognitive disorders caused by organic brain deficiencies. Thanks to the investigations in clinical neuropsychology, today we possess priceless knowledge of cognitive functioning of the healthy as well as of the ill population [1].

Despite the fact that the last decades of the previous century were the flourishing era for neuropsychological examinations, modern, subtle findings crave for more sensitive instruments for detecting and classifying various disorders. This is why neuropsychological diagnostics is experiencing further growth. The need for creating new neuropsychological tests which would be able to examine separate brain functions more specifically and precisely is always present. The variety of test materials allows complete insight of the domain of higher cortical functions in every particular case. Qualitative observations through which the data that cannot be seen through test scores is gathered, as well as the complementary type of examination, is as important as the testing alone.

When research design is being created, the first question that is being imposed is the choice of subjects that would constitute the sample. In clinical studies, the sample is usually not formed randomly because it is necessary to establish the criteria for inclusion and exclusion of subjects. Besides these criteria that stem from research design, some other factors that come from the exact nature of neuropsychological tests should be taken into consideration.

In the first place, when choosing the subjects it is advisable that their educational level should be higher than primary. Lower education can contribute to lower test scores, especially when verbal abilities are being examined, like, for example, level of general knowledge, linguistic functions, etc. One of the possible solutions to make the influence of lower education on test achievements as least as possible is to include more educated subjects into research project.

In the second place, the choice of tests should be planned in a way that it consistently follows research design. If it is planned for the study to cover the overall neuropsychological functioning, than the following should be kept in mind - in order for brain functions to be properly examined, it is necessary to adopt the point which will enable us to examine each of them separately, specifically and sensitively enough, while the examination should be reliable and objective. What should be available in order to establish the parameters of cognitive status and functional impairment level, are data about wide range of measuring which contain functions which are impaired, slightly or largely, and the ones that remained untouched [2]. To make it short, it is beneficial to use wide range of tests in neuropsychological researches. Of course, this need is not imposed if the aim of the examination is the evaluation of only one, isolated neuropsychological function. In such cases, larger number of tests for examining specific function should be used, in order to come up to the more valid and reliable conclusion about the level of its impairment or preservation.

In the third place, the choice of tests depends to some degree on the age of the subject. It is known that cognitive processing speed declines with getting old, more precisely with the increase of age. Many authors [e.g. 3-5], have written about this phenomenon, so it can be said that time-limited test tasks might lead to discrimination of elderly subjects. If the subjects included in the research are older (65 and above), it is favorable for the majority of tests to contain tasks that are cognitively more demanding than tasks which are time-limited. Although processing speed is an important aspect of intellectual abilities, the aim of neuropsychological evaluation is to examine maximum performance, more precisely to establish the top limit of cognitive abilities. The limit will always be slightly higher than the results achieved on tests. This is why testing of cognitive limits with 
Citation: Leposavic I, Leposavic-Stankovic L, Djuric-Jocic D (2015) Neuropsychological Researches: Experiences and Comments. J Psychiatry

Page 2 of 2

prolonged testing even when the time-limit for the task ends is allowed in neuropsychological approach.

In the fourth place, the topic of ecological validity in the scope of evaluation of the elderly and people with brain impairments has been in the peak of interest in the recent years [6,7], because the crucial question whether they are capable of living independently has been imposed. In order to come up with the reliable conclusion about everyday cognitive functioning of the subjects who consist the sample and in order to give possible referrals for neuropsychological rehabilitation, it is impossible to neglect the question of ecological validity of chosen tests.

Finally, tests and scales that are used in psychological evaluation and investigations have certain restrictions, so the fact that this applies to neuropsychological tests as well is no wonder. One of these restrictions applies to the construction of the tests which specificity is being disturbed by the impossibility of excluding the factors which do not pertain to the measured construct [8]. Neuropsychological tests of higher cortical processes which are very complicated include the evaluation of various functions, not of only individual, separate ones [9]. In this way, for example, it is possible that lower scores on tests which examine memory lead to the wrong conclusions about impaired memory of the subjects who constitute the sample; unless some other test parameters are taken into account. Memory is a vulnerable function, so it is possible that primary attention disorder secondary impair memory which, in cases like this, is not disrupted by itself [10]. This neuropsychological tests restriction should always be kept in mind when analyzing and interpreting the research results, to avoid making wrong conclusions. Nevertheless, some other factors that stem from the subjects' attitude towards tests (e.g. poor effort, malingering, exaggeration etc.) [11] influence test achievements, so it is necessary to pay attention to these factors while interpreting the results or to exclude these subjects from the sample. Researches in clinical neuropsychology are challenging but demanding as well, so it is not always possible to stick to the investigation design if it is over ambitiously created. This mini review is based on our experience in both clinical practice and researches and it reflects our opinion about possible limits in this area, with the suggestions how those limits can be overcome.

\section{References}

1. Ocic G (2012) Klinicka neuropsihologija. Zavod za udzbenike, Beograd.

2. Pavlovic DM (2012) Neuropsihologija Bihevioralna neurologija i Neuropsihologija. Orionart, Beograd.

3. Kerchner GA, Racine CA, Hale S, Wilheim R, Laluz V, et al. (2012) Processing Speed in Older Adults: Relationship with White Matter Integrity. PLOS ONE 7: 1-10.

4. Eckert MA (2011) Slowing Down: Age-Related Neurobiological Predictors of Processing Speed. Frontiers in Neuroscience 5: 1-13.

5. Salthouse A (2000) Aging and measures of processing speed. Biol Psychol 54: 35-54.

6. Canini M, Battista P, Della Rosa PA, Catricala E, Salvatore C, Gilardi MC, Castiglioni I (2014) Computerized Neuropsychological Assessment in Aging: Testing Efficacy and Clinical Ecology of Different Interfaces. Comput Math Methods Med 2014.

7. Tarnanas I, Schlee W, Tsolaki M, Müri R, Mosimann U, Nef T (2013) Ecological Validity of Virtual Reality Daily Livig Activities Screening for Early Dementia: Longitudinal Study. JMIR Serious Games 1: e1.

8. Lezak, MD (1995) Neuropsychological assessment. (3rd ed.) New York, Oxford University Press.

9. Leposavic I, Leposavic Lj, Saula-Marojevic B (2010) Neuropsychological assessment: computerized batteries or standard tests. Psychiatr Danub 22: $149-152$.

10. Leposavic I, Leposavic Lj, Gavrilovic P (2010) Depression vs. Dementia: A comparative analysis of neuropsychological functions. Psihologija 43: 137-153.

11. Dandachi-FitzGerald B, Ponds RWHM, Merten T (2013) Symptom Validity and Neuropsychological Assessment: A Survey of Practices and Beliefs of Neuropsychologists in Six European Countries. Arch of Clin Neuropsychol 28: 771-783. 